\title{
An Adaptive Approach to Managing Knowledge Development in a Project-based Learning Environment
}

\author{
Oleg Tilchin ${ }^{1}$, Mohamed Kittany ${ }^{1}$ \\ ${ }^{1}$ Al-Qasemi Academic College of Education, Baqa El-Gharbieh, Israel \\ Correspondence: Oleg Tilchin, Computer Science Department, Academic College of Education, P.O. Box \\ 124,BaqaEl-Gharbieh 30100, Israel.
}

Received: June 20, 2016

Accepted: July 25, 2016

Online Published: August 1, 2016

doi:10.11114/jets.v4i10.1681

URL:http://dx.doi.org/10.11114/jets.v4i10.1681

\begin{abstract}
In this paper we propose an adaptive approach to managing the development of students' knowledge in the comprehensive project-based learning (PBL) environment. Subject study is realized by two-stage PBL. It shapes adaptive knowledge management $(\mathrm{KM})$ process and promotes the correct balance between personalized and collaborative learning. The six-step approach comprises planning the development of students' knowledge providing the needed instructional materials; KM of students by teaching a subject in the PBL environment leading to acquiring subject knowledge while work on a sample-project every student of a study group; sustaining adaptive self-formation of knowledge heterogeneous collaborative groups through sharing accountability among students for results of performing project tasks; guiding collaborative performance of group projects aimed at setting adaptive assessments of knowledge for collaborative groups and individual students based on the current state of knowledge, dynamic choice of control tests for individual students and projects of suitable complexity for collaborative groups, and adjustment of an instructor's control questions to complexity levels of projects performed by groups; assessing the knowledge gained by each student after completion of a group project by the control tests of different complexity; and evaluating knowledge dynamics of students through the proposed coefficient of knowledge development.
\end{abstract}

Keywords: adaptive knowledge management, project-based learning

\section{Introduction}

Specialists having deep knowledge and higher order thinking competencies are needed for the modern knowledge-based economy (Dym et al., 2005; Larmer\&Mergendoller, 2015). A constructivist approach to teaching using project-based learning (PBL) is required for training such specialists (Thomas, 2000; Solomon, 2003; Barkley, Cross \& Howell, 2004; Krauss \&Boss, 2013).

The PBL effectiveness can be promoted by a comprehensive learning environment. The comprehensive environment is characterized as student-centered, knowledge -centered, community-centered, assessment-centered, computer-centered, nd accountability-centered (Bransford, Brown \& Cocking, 1999; Jonassen, 2004; Anderson, 2008; Tilchin\&Kittany, 2016).

The student-centered characteristic implies students' independence in learning by doing, combining individual and collaborative learning, encouraging critical thinking, monitoring existing student knowledge both the instructor and the students, and adaptability to each student (Felder \& Brent, 2001; Solomon, 2003; Barkley, Cross \& Howell, 2004; Savery, 2006; Ravitz, 2009; Bender, 2012).

The knowledge-centered characteristic means the instructor's fostering knowledge development in students. Knowledge can be represented in four levels: know-what, know-how, know-why, care-why (Quinn, Anderson \& Finkelstein, 1998; Tiwana, 1999). The knowledge levels have their determined roles in education. Thus, the know-what level represents cognitive knowledge; the know-how level deals with practical problems of design based on a synthesis of knowledge; the know-why level refers to deep knowledge of complex cause-and-effect relationships; the care-why level embodies self-motivated creativity. Know-why and care-why knowledge levels present higher-order knowledge.

The community-centered characteristic represents group work in online learning environment to develop knowledge collaboratively (Coakes\& Clarke, 2006; Anderson, 2008). The assessment centered characteristic means high quantity 
and quality of assessments while maintaining learner interest to knowledge development (Shavelson, 2009). An assessment should be guided and adaptive process. The computer-centered characteristic denotes computer support of PBL through using possibilities of computer technologies for providing effective learning and decreasing an extra-heavy workload for an instructor (Stahl, 2006). The accountability-centered characteristic means taking accountability of the students for learning results. It requires group interdependence, motivation, compatibility, and sociability (Garrison, 1992; Reeves, 2004; Krantz\&SooHoo, 2005; Stanton \& Fairfax, 2007; Doyle \&Taqq, 2008).

Knowledge management (KM) of students while a course study in the comprehensive PBL environment is based on realization of KM concept (Sallis\& Jones, 2002; Livingstone \&Guile, 2012; Rooney, McKenna\&Liesh, 2014; Altinay, Dagli\&Kasimoglu, 2015). According to the concept, knowledge development of students is attained through knowledge creation, knowledge sharing, and knowledge utilization (Tiwana, 1999; Petrides\&Nodine, 2003; Dalkir\&Liebowitz, 2011; Edwards, 2015).

Knowledge development can be promoted by adaptive management of knowledge development by using the results of multifaceted assessment (Sherif, 2006; Mcinerney\& Day, 2007;Zaim H., Tatoglu, \&Zaim S., 2007; Dalkir\&Liebowitz, 2011). It requires carrying out theoretical research to devise an adaptive approach. The goal of the proposed approach is to elaborate and evaluate the process of adaptive management of knowledge development of students in the comprehensive PBL environment. It will allow us to create a practical method and a supporting system for adaptive management of the development of students' knowledge while PBL.

\section{Related Research}

The researches are examined here relative to various aspects of promoting students' knowledge development. The aspects are management of PBL, knowledge management, and adaptive learning support.

The principles of managing PBL are determined by Mergendoller and Thomas (2005). The authors grouped their under seven categories: time management, getting started, establishing a culture that stresses student self-management, managing student groups, working with others outside the classroom, getting the most out of technological resources, and assessing students and evaluating projects. Mergendoller, Markham, Ravitz and Larmer (2006) developed a "pervasive" four stage management approach to guide students effectively through the PBL process. The stages are project planning, project launch, guided inquiry and product creation, and project conclusion. Management activities guiding and facilitating students' PBL are determined relative to each stage.

The management of student groups is aimed at facilitating group interactions. Various methods and means of facilitation of group interactions are suggested in works (Ettington\& Camp, 2002; Dongsik\&Seunghee, 2002; Lopez et al., 2002; Weinberger et al., 2003).Markham (2012) suggested an approach to specific management of project performance directed towards building collective knowledge through collaboration.

Prusak and Cranefield (2016) suggested practices for personal knowledge management (PKM) in order to keep ideas and skills current and to remain flexible and innovative. Garner (2010) set relation between personal KM and learning. The author proposed the seven components of PKM and connected them with elements of a learning framework created by Oliver and Herrington (2001). The framework comprises three critical elements: learning content, learning activities, and learning support. The components of PKM are retrieving content, assessing information, organizing the information, analyzing the information, collaboration, securing information, presenting information.

Vasilyeva, Pechenizkiy and Puuronen (2005) represented a KM process in adaptive e-learning system. The goal of this process is to make the use of an adaptation mechanism more effective. The authors divided the KM process into five main stages: knowledge creation and acquisition, knowledge organization and storage, knowledge distribution and integration, knowledge adaptation and application, and knowledge evaluation, validation and refinement. The adaptation mechanism provides the adaptation of the learning materials' content presentation according the proficiency of the students.

Burgos, Tattersall and Koper (2006) described a modern adaptive system providing the adaptation based on learning behavior of students, personalized and collaborative learning based on student learning goals, and adjusting the instruction type to the needs or preferences of the student. Brusilovsky and Maybury (2002) defined an adaptive system as one that distinguishes between users including their knowledge goals and interests, and an adaptable system as one requiring the user to specify exactly how the system should be different. Mennin (2007) investigated a PBL group as a complex adaptive system. A student group is complex in that it is dynamic network of interactions among students, and it is adaptive in that the students individually and a group are altered corresponding to the change.

Burgos, Tattersall and Koper (2006) proposed different types of adaptive learning support including problem-solving support, information filtering, collaborative grouping of students, adaptive testing and real-time course modifications by the instructor to meet the specific needs of students. Soller (2007) described various tools of adaptive support for 
collaborative learning to conduce interactions, motivation for knowledge sharing, and collaboration management. Brusilovsky and Peylo (2003) considered adaptive collaboration support providing an interactive support of a collaboration process assisting an individual student in solving a problem, and adaptive group formation using knowledge about collaborating peers.

Aguilar and Kaijiri (2007) developed an adaptive computer-based assessment system, which provides initial, formative, and summative assessments. The system generates questions adapted to the learners' knowledge. Lazarinis, Green and Pearson (2010) proposed computerized adaptive testing system, which adapts based on student performance, instructional goals, and test participants existing knowledge of the subject matter. The authors provided examples where instructors set different adaptive assessments for various scenarios. Papanastasiou (2014) defined adaptive assessment as one that is specific for each student and takes into account that student's previous performance, thus making it more accurate in terms of individual ability.

The publications discussed above indicate that no an adaptive approach exists to managing knowledge development in the comprehensive PBL environment. The proposed adaptive approach to managing knowledge development is aimed at promoting effective development of student knowledge due to: detailed planning knowledge development of students, creating and applying a mechanism for adaptive management of the development of students' knowledge, realizing subject study through two-stage PBL process, and inducing, guiding, and facilitating knowledge development.

\section{The Adaptive Approach to Managing the Development of Students' Knowledge}

The goal of the approach is to intensify subject study through guiding, inducing, and facilitating the development of students' knowledge in the comprehensive PBL environment. The adaptive management of knowledge development is aimed at knowledge creation, knowledge sharing, and knowledge utilization. It comprises adaptive self-formation of knowledge-heterogeneous collaborative groups of students, adaptation of an instructor's assessments to knowledge dynamics of individual students and collaborative groups, adaptive choice of the projects of suitable complexity for the collaborative groups, dynamic choice of control tests for monitoring and assessing individual students, and adjustment of an instructor's control questions to complexity levels of the projects performed by the collaborative groups.

Adaptive management of the development of students' knowledge is realized while the two- stage PBL. The purpose of the first stage is promoting creation of knowledge relevant to subject, and fostering adoption of specificity of the comprehensive PBL environment while performing a sample-project by each student of the class. The purpose of the second stage is promoting the development of students' knowledge through knowledge sharing and knowledge utilization while performance of projects by collaborative groups.

The approach intends consistent performance of the determined steps.

Step1. Planning the development of students' knowledge

The aim is preparing instructional material needed for adaptive management of the development of students' knowledge while realizing a two- stage process of the PBL learning.

At first, a subject specification taking into account the requirements for a student is created. After studying a subject, a student should know its concepts, get results by applying theoretical knowledge, explain cause-and-effect relationships, and make creative decisions. The specification involves list the subject topics and an aggregate of knowledge components representing subject-relevant knowledge. A knowledge component corresponds with a topic. A knowledge component includes the sub-components know-what $\left(\mathrm{k}^{1}\right)$, know-how $\left(\mathrm{k}^{2}\right)$, know-why $\left(\mathrm{k}^{3}\right)$, and care-why $\left(\mathrm{k}^{4}\right)$ corresponding with the aforementioned knowledge levels. Hence, the knowledge component relevant to $\mathrm{j}$ topic is $\mathrm{K}_{\mathrm{j}}=$ $\left\langle\mathrm{k}_{\mathrm{j}}{ }^{1}, \mathrm{k}_{\mathrm{j}}{ }^{2}, \mathrm{k}_{\mathrm{j}}{ }^{3}, \mathrm{k}_{\mathrm{j}}^{4}\right\rangle$, where $\mathrm{j}=1, \ldots, \mathrm{n} ; \mathrm{n}$ is the quantity of subject topics.

Next, correspondence between a subject and a sample-project regarding the required knowledge is determined. Knowledge needed for performance of the sample-project (sample project-relevant knowledge) should be equal to subject-relevant knowledge. A set of project tasks corresponds with a set of subject topics. It means that one task or some tasks of a sample-project should correspond to each subject topic. Task-relevant knowledge (it is knowledge needed for performance of a task) is defined depending on the quantity of the tasks corresponding with the topic. The order of performing project tasks is conformed to the order of teaching subject topics.

Then, the initial assessments of students' knowledge regarding different sub-components of knowledge are set. The more initial assessments are set for know what and know-how sub-components for inducing students to subject study. Assessments of students' knowledge regarding the sample-project tasks are determined by splitting the initial assessments.

At last, a specification of the projects of different complexity levels is created. They are intended for performance by student collaborative groups. The more complicated project requires more higher-order knowledge represented by 
know-why, and care-why components for its performance. Control tests for examination of students' knowledge after completion of the sample-project and the group projects are prepared.

Example1.There are five subject topics. Hence, subject-relevant knowledge is represented by five knowledge components. Two project tasks correspond with the first subject topic. One project task corresponds with each of other subject topics.

The initial assessment for studying of a subject is $100 \%$.The initial assessments for studying of a subject regarding knowledge sub-components are a result of splitting the subject assessment. They are represented in Table 1.

Table 1. The initial assessments for studying of a subject

$\begin{array}{cc}\text { The knowledge sub- components } & \text { Assessments \% } \\ \text { know-what }\left(\mathrm{k}^{1}\right) & 30 \\ \text { know-how }\left(\mathrm{k}^{2}\right) & 40 \\ \text { know-why }\left(\mathrm{k}^{3}\right) & 20 \\ \text { care-why }\left(\mathrm{k}^{4}\right) & 10\end{array}$

Since the subject contains five subject topics, the fixed assessments of topic-relevant knowledge of a student regarding the knowledge sub-components are equal to $6 \%, 8 \%, 4 \%$, and $2 \%$, accordingly. If one task of a sample-project corresponds with one subject topic, then fixed assessments of task-relevant knowledge regarding the knowledge subcomponents are equal to $6 \%, 8 \%, 4 \%$, and $2 \%$, accordingly. Since, two project tasks correspond with the first subject topic, fixed assessments of task-relevant knowledge each of tasks are equal to 3\%, 4\%,2\%, and 1\%, accordingly.

Correspondence between the project complexity level and the range of cumulative knowledge assessments of students from a potential collaborative group (a group includes three students) is represented by Table 2.

Table 2. Correspondence between the project complexity levels and the assessment ranges

\begin{tabular}{cc}
\hline The project complexity level & The assessment range \\
\hline 1 & $150-200$ \\
2 & $201-250$ \\
3 & $251-300$ \\
\hline
\end{tabular}

Step 2. KM of students by teaching the subject

The aim is realizing and assessing the KM process by teaching the subject in the PBL environment. Teaching the subject consists in submitting the subject matter while work on the sample-project every student of a study group and guiding project performance to promote adoption of specificity of the comprehensive PBL environment. The subject matter is submitted in synchrony with the performance of the sample project tasks since each subject topic corresponds to one or more of these tasks.

An instructor assesses a student's knowledge after completion of the sample-project through control questions regarding the various knowledge sub-components. Correct answers of a student at a certain knowledge sub-component indicate that he has acquired knowledge at this sub-component. That means that a student has met the initial assessment set for this sub-component. If answers of a student are not entirely correct then the corresponding assessment is marked. Lastly the sum of formative assessments of each student's knowledge for all knowledge components is calculated and that is his (her) total formative assessment of knowledge.

Example 2. The formative assessments of the knowledge built by students while performance of the sample-project is represented in Table3. Row names correspond to the knowledge sub-components regarding the project tasks. Lower and upper indices denote numbers of the tasks and the knowledge sub-components, accordingly. Initial assessments of the knowledge sub-components are shown. Column names correspond to student IDs. Knowledge regarding a certain sub-component built by a student is marked at the intersection of a row and a column. 
Table 3. The formative assessments of the students'knowledge after completion of a sample project

\begin{tabular}{|c|c|c|c|c|c|c|c|}
\hline \multirow{2}{*}{$\begin{array}{c}\text { The } \\
\text { sample-project } \\
\text { tasks }\end{array}$} & \multirow{2}{*}{$\begin{array}{l}\text { The initial } \\
\text { assessments of } \\
\text { knowledge } \\
\text { sub-components }\end{array}$} & \multicolumn{6}{|c|}{ The formative assessments of the students' knowledge } \\
\hline & & $\mathrm{S}_{1}$ & $\mathrm{~S}_{2}$ & $\mathrm{~S}_{3}$ & $\mathrm{~S}_{4}$ & $\mathrm{~S}_{5}$ & $\mathrm{~S}_{6}$ \\
\hline \multirow{4}{*}{$\mathrm{Z} 1$} & $\begin{array}{c}\text { suo-componts } \\
\mathrm{K}_{11}{ }^{1}(3 \%)\end{array}$ & 2 & 3 & 3 & 2 & 2 & 2 \\
\hline & $\mathrm{K}_{11}(4 \%)$ & 3 & 4 & 2 & 2 & 1 & 2 \\
\hline & $\mathrm{K}_{11}(2 \%)$ & 1 & 2 & 0.5 & 1 & 0.5 & 2 \\
\hline & $\mathrm{K}_{11}(1 \%)$ & 0.5 & 1 & 1 & 1 & 0.5 & 0.5 \\
\hline \multirow{4}{*}{$\mathrm{Z} 2$} & $\mathrm{~K}_{12}{ }^{1}(3 \%)$ & 3 & 3 & 2 & 3 & 2 & 2 \\
\hline & $\mathrm{K}_{12}(4 \%)$ & 3 & 3 & 2 & 4 & 2 & 3 \\
\hline & $\mathrm{K}_{12}(2 \%)$ & 1 & 1 & 0.5 & 1 & 0.5 & 1 \\
\hline & $\mathrm{K}_{12}(1 \%)$ & 0.5 & 1 & 1 & 1 & 0.5 & 0.5 \\
\hline \multirow{4}{*}{$\mathrm{Z} 3$} & $\mathrm{~K}_{3}{ }^{1}(6 \%)$ & 6 & 5 & 6 & 6 & 5 & 5 \\
\hline & $\mathrm{K}_{3}<(8 \%)$ & 4 & 6 & 7 & 6 & 4 & 4 \\
\hline & $\mathrm{K}_{3} 3(4 \%)$ & 3 & 3 & 1 & 3 & 2 & 1 \\
\hline & $\mathrm{K}_{3}^{4}(2 \%)$ & 1 & 2 & 1 & 2 & 1 & 1 \\
\hline \multirow{4}{*}{ Z4 } & $\mathrm{K}_{4}{ }^{1}(6 \%)$ & 5 & 6 & 3 & 5 & 4 & 4 \\
\hline & $\mathrm{K}_{4}<(8 \%)$ & 8 & 8 & 4 & 7 & 5 & 6 \\
\hline & $\mathrm{K}_{4}(4 \%)$ & 3 & 4 & 2 & 2 & 1 & 3 \\
\hline & $\mathrm{K}_{4}^{4}(2 \%)$ & 2 & 1 & 1 & 1 & 1 & 2 \\
\hline \multirow{3}{*}{ Z5 } & $\mathrm{K}_{5}{ }^{1}(6 \%)$ & 4 & 5 & 5 & 4 & 6 & 6 \\
\hline & $\mathrm{K}_{5}{ }^{2}(8 \%)$ & 5 & 8 & 6 & 6 & 5 & 7 \\
\hline & $\mathrm{K}_{5}{ }^{\circ}(4 \%)$ & 2 & 3 & 2 & 2 & 1 & 2 \\
\hline & $K_{5}^{4}(2 \%)$ & 1 & 2 & 2 & 2 & 1 & 1 \\
\hline \multirow{4}{*}{ Z6 } & $\mathrm{K}_{6}{ }^{1}(6 \%)$ & 6 & 6 & 4 & 6 & 5 & 5 \\
\hline & $\mathrm{K}_{6}{ }^{2}(8 \%)$ & 7 & 8 & 5 & 5 & 4 & 4 \\
\hline & $\mathrm{K}_{6}{ }^{\circ}(4 \%)$ & 3 & 4 & 1 & 2 & 2 & 1 \\
\hline & $\mathrm{K}_{6}{ }^{4}(2 \%)$ & 1 & 1 & 1 & 1 & 1 & 1 \\
\hline
\end{tabular}

The formative assessments of the students' knowledge regarding the knowledge sub-components are represented by Table 4. The last row of Table4 contains the total formative assessments of student knowledge.

Table 4. The formative assessments of the students' knowledge regarding knowledge sub-components

\begin{tabular}{ccccccc}
\hline The knowledge & \multicolumn{5}{c}{ The formative assessments of the students' knowledge } \\
\cline { 2 - 3 } & $\mathrm{S}_{1}$ & $\mathrm{~S}_{2}$ & $\mathrm{~S}_{3}$ & $\mathrm{~S}_{4}$ & $\mathrm{~S}_{5}$ & $\mathrm{~S}_{6}$ \\
know-what & 26 & 28 & 23 & 25 & 24 & 24 \\
know-how & 30 & 37 & 26 & 35 & 21 & 26 \\
know-why & 13 & 17 & 7 & 11 & 7 & 10 \\
care-why & 6 & 8 & 7 & 8 & 5 & 6 \\
The total formative & 75 & 90 & 63 & 79 & 57 & 66 \\
assessments & & & & &
\end{tabular}

Step 3. Sustaining self-formation of collaborative groups

The aim is sustaining self-forming knowledge heterogeneous collaborative groups through taking accountability of students for results of performing project tasks. Self-forming collaborative groups is sustained by instructor requirements. The requirements induce students for knowledge development through collaborative interactions while performance of group projects.

The requirements are:

- Maximal allowed quantity of students in a collaborative group is fixed. It conduces to intra-group interactions fostering knowledge transfer.

- One member of a collaborative group is accountable for performing a project task. It creates personal accountability of students for qualitative and timely performance of the tasks.

- A student may be accountable for performing fixed quantity of the project tasks corresponding with different subject topics. It provides sharing and diversity accountability.

- Taking into account personal characteristics of students. It enables compatibility of students.

- The students of a collaborative group participate in performance of all project tasks. It encourages intensive collaboration of students.

Self-forming knowledge heterogeneous collaborative groups involves self-evaluation of the students and coordination of self-evaluation outcomes with taking into account the requirements.

A student realizes self-evaluation of his (her) willingness and desire to take accountability for results of performance of 
determined project tasks. The willingness to be accountable is resulted by holding knowledge needed for performance of a task. The desire to take accountability is caused by the determined requirements.

A table reflecting results of self-evaluation of the willingness and the desire of students to take accountability for project task performance can be created. The rows of the table correspond to the students. The columns of the table correspond to the subject topics and the project tasks that should be performed. Intersection of a row and a column contains result of self-evaluation. The intersection is marked by symbol "A", if a student is willing and desiring to take accountability for result of performing a task.

Example 3. A sequence of the tasks $z_{1}, z_{2}, \ldots . ., z_{6}$ of the group project is determined. The task number reflects the priority of its performance. A study group contains 6 students. Maximal allowed quantity of students in the collaborative group is equal to three. Then, the quantity of collaborative groups must be equal to two. Each student should be accountable for performing two project tasks. The self-evaluation outcomes are presented by Table 5. Thus, the student $\mathrm{s}_{1}$ makes decision to take accountability for the results of performing the tasks $z_{1}$ and $z_{3}$, corresponding with the first and the second subject topic, accordingly.

Table 5.The self-evaluation outcomes

\begin{tabular}{|c|c|c|c|c|c|c|}
\hline \multirow{3}{*}{ The students } & \multicolumn{6}{|c|}{ The subject topics and project tasks } \\
\hline & & & 2 & 3 & 4 & 5 \\
\hline & $\mathrm{z}_{1}$ & $\mathrm{z}_{2}$ & $z_{3}$ & $\mathrm{z}_{4}$ & $\mathrm{z}_{5}$ & $\mathrm{z}_{6}$ \\
\hline $\mathbf{S}_{2}$ & $\mathrm{~A}$ & & A & & & \\
\hline $\mathbf{s}_{\mathbf{3}}$ & & & A & & A & A \\
\hline $\mathbf{S}_{\mathbf{4}}$ & & A & & & A & \\
\hline $\mathbf{S}_{5}$ & & A & & A & & \\
\hline $\mathbf{S}_{6}$ & & & & A & & A \\
\hline
\end{tabular}

The table containing the self-assessment outcomes is manifested. The objective of manifestation is to foster coordination of taken accountability of students for the results of performing the project tasks so to complete self-forming collaborative groups.

Coordination is realized through discussion of students with participation of an instructor. During discussion, every student compares tasks for which he would be accountable with those tasks chosen by peers and the performance of which they would be accountable. The aim of comparison is to form collaborative groups for performing the tasks through coordination of result-based personal accountability of students.

The tasks selected earlier by a student can be replaced by other tasks due to coordination with peers. If some students want to be accountable for performing the same task, despite coordination of their outcomes, then the instructor determines the student who should be accountable for the result.

If there is not a student who shows desire to take accountability for performing a task, the instructor delegates accountability to the most suitable student. Hence, forming heterogeneous collaborative groups leading to the building complete accountability of students for results of performing all project tasks through compared analysis of students' choices is realized.

Example 4.Students $s_{1}$ and $s_{2}$ are incompatible. It allows forming the composition versions of collaborative groups. The composition versions and result their analysis based on data from Table 5 are represented by Table 6 .

Table 6. Analysis of the collaborative group versions

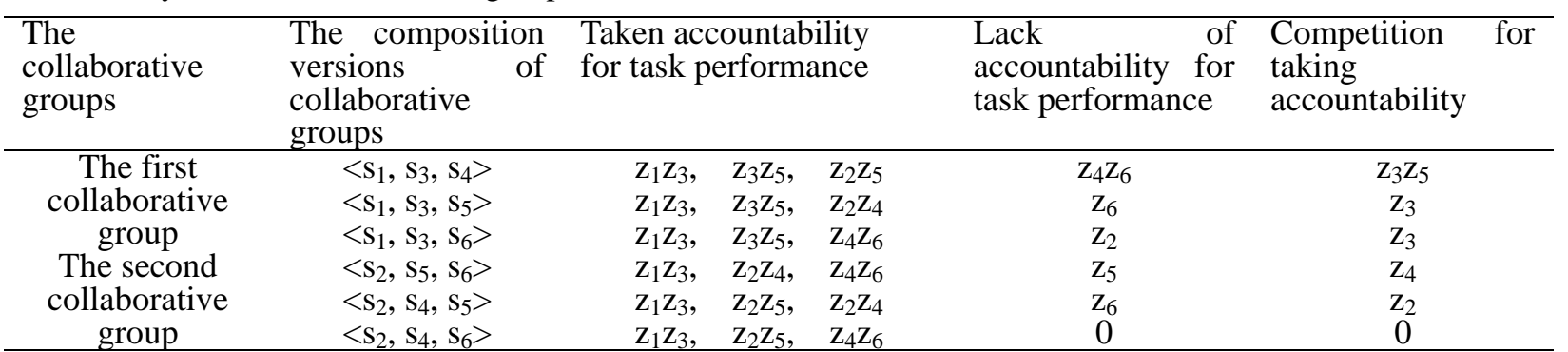

Analysis of the possible composition versions of first collaborative group allows to conclude that the most preferable versions are $\left\langle\mathrm{s}_{1}, \mathrm{~s}_{3}, \mathrm{~s}_{5}\right\rangle$ and $\left\langle\mathrm{s}_{1}, \mathrm{~s}_{3}, \mathrm{~s}_{6}\right\rangle$ since there are lack of accountability for performance of a single task and competition for taking accountability for a single task for each of these versions.

If the composition version $\left\langle\mathrm{s}_{1}, \mathrm{~s}_{3}, \mathrm{~s}_{5}\right\rangle$ of the first collaborative group is chosen then second collaborative group includes the students $\mathrm{s}_{2}, \mathrm{~s}_{4}$, and $\mathrm{s}_{6}$. If the composition version $\left\langle\mathrm{s}_{1}, \mathrm{~s}_{3}, \mathrm{~s}_{6}\right\rangle$ the first group is chosen then second collaborative 
group includes the students $s_{2}, s_{4}$, and $s_{5}$. Analysis of the composition versions (Table 6) of the second collaborative group allows concluding that the composition version $\left\langle s_{2}, s_{4}, s_{6}\right\rangle$ is the most preferable. It determines choice of first collaborative group. Hence, the formed collaborative groups are $\left\langle\mathrm{s}_{1}, \mathrm{~s}_{3}, \mathrm{~s}_{5}\right\rangle$ and $\left\langle\mathrm{s}_{2}, \mathrm{~s}_{4}, \mathrm{~s}_{6}\right\rangle$.

Yet, the students $s_{1}$ and the $s_{3}$ from the first collaborative group are competing for taking accountability for performing task $z_{3}$ and there is lack of accountability for performance of the task $z_{6}$ (Table 6). Coordination their self-assessment outcomes through discussion with the participation of an instructor is realized. As a result of coordination, the student $s_{3}$ takes accountability for result of performing the task $z_{6}$ instead of the task $z_{3}$. The accountability outcomes of the students of the formed collaborative groups are represented by Table 7 . The accountability outcomes satisfy the above mentioned requirements.

Table 7. The accountability outcomes of the collaborative groups' students

\begin{tabular}{|c|c|c|c|c|c|c|c|}
\hline \multirow{3}{*}{$\begin{array}{c}\text { The collaborative } \\
\text { groups }\end{array}$} & \multirow{3}{*}{ The students } & \multicolumn{6}{|c|}{ The subject topics and project tasks } \\
\hline & & & & 2 & 3 & 4 & 5 \\
\hline & & $\mathrm{z}_{1}$ & $\mathrm{Z}_{2}$ & $\mathrm{z}_{3}$ & $\mathrm{Z}_{4}$ & $\mathrm{Z}_{5}$ & $\mathrm{z}_{6}$ \\
\hline $\begin{array}{c}\text { The first } \\
\text { collaborative }\end{array}$ & $\mathbf{S}_{1}$ & A & & A & & & \\
\hline groups & $\mathbf{S}_{3}$ & & & & & $\mathrm{~A}$ & A \\
\hline & $\mathbf{S}_{5}$ & & A & & A & & \\
\hline The second & $\mathbf{S}_{2}$ & A & & A & & & \\
\hline collaborative & $\mathbf{S}_{4}$ & & A & & & A & \\
\hline groups & $S_{6}$ & & & & A & & A \\
\hline
\end{tabular}

Step 4. Guiding collaborative performance of group projects

The aim is assigning projects for collaborative groups and setting adaptive assessments of knowledge for collaborative groups and individual students.

Assigning a project for a collaborative group is resulted by choice of a project of suitable complexity level through comparison between complexity levels of the projects and the total formative assessments of the groups' knowledge. Formative knowledge assessment of the collaborative group is calculated as sum of the formative knowledge assessments received by students of the group. The project of higher complexity level is assigned for the collaborative group having the more formative assessment.

Example 5.On the basis of data from Table 4, the total formative knowledge assessments of the first and the second collaborative groups are 195, and 235, accordingly. Then, the projects of the first and second complexity levels are assigned for the first and the second collaborative groups, accordingly (Table 2).

Since at the second stage of PBL the instructor's main attention is devoted to developing higher order knowledge, adaptive assessments of student knowledge regarding know-why and care-why levels should be more than adaptive assessments regarding know -what and know-how levels.

The adaptive knowledge assessment of the collaborative group is set by taking into account of its total formative assessment. According to that, the more adaptive assessment of knowledge regarding know-why and care-why sub-components is set for the collaborative group having the more total formative assessment of knowledge.

Example 6.An adaptive assessment of knowledge regarding the knowledge component is set equal to $100 \%$.The total formative assessments of knowledge of the first and the second collaborative groups are 195, and 235, accordingly (Example 5). Consequently, the more adaptive assessment of both know-why and care-why sub-components is set for second group. The adaptive assessments of the collaborative groups regarding the knowledge sub-component couples are represented by Table 8 .

Table 8 . The adaptive assessments of the collaborative groups

\begin{tabular}{ccc}
\hline The knowledge sub-components & $\begin{array}{c}\text { The adaptive assessments of the } \\
\text { first group }\end{array}$ & $\begin{array}{c}\text { The adaptive assessments of } \\
\text { the second group }\end{array}$ \\
\hline know-what and know-how & 40 & 30 \\
know-why and care-why & 60 & 70 \\
\hline
\end{tabular}

Knowledge dynamics of the collaborative groups after completion of the sample project is determined through a coefficient of knowledge development by formula:

$$
\delta\left(\mathrm{k}_{\mathrm{j}}\right)=\left(\mathrm{g}\left(\mathrm{k}_{\mathrm{j}}\right)-\mathrm{g}^{\mathrm{b}}\left(\mathrm{k}_{\mathrm{j}}\right)\right) / \mathrm{g}^{\mathrm{b}}\left(\mathrm{k}_{\mathrm{j}}\right) \quad, \quad-1<\delta\left(\mathrm{k}_{\mathrm{j}}\right) \leq 0
$$

where

$\mathrm{g}\left(\mathrm{k}_{\mathrm{j}}\right)$ is a formative assessment of a collaborative group regarding $\mathrm{k}_{\mathrm{j}} \mathrm{knowledge}$ sub-component, $\mathrm{j}=1,2,3,4 \mathrm{~g}^{\mathrm{b}}\left(\mathrm{k}_{\mathrm{j}}\right)$ is a basic(an initial) assessment of a group regarding $\mathrm{k}_{\mathrm{j}}$ sub-component. 
If the value of the knowledge development coefficient of a group regarding some sub-component is lower, then its adaptive knowledge assessment regarding this sub-component should be more.

Example7. The initial group assessments regarding know-what, know-how, know-why, and care-why knowledge sub-components are 90, 120, 60, and 30, accordingly (Table 1).

The formative assessments of the first collaborative group regarding know-what, know-how, know-why, and care-why sub-components are 73, 77, 27, and18, accordingly (Table 4). Similarly, the formative assessments of the second collaborative group regarding the knowledge sub-components are 77, 98, 38, and 22, accordingly.

The values of the knowledge development coefficient regarding the knowledge sub-components determined by formula (1) are represented by Table 9.

Table 9. The values of the knowledge development coefficient

\begin{tabular}{ccccc} 
The name of & \multicolumn{3}{c}{ Thevalues of the knowledge development coefficient regarding sub-components } \\
\cline { 2 - 5 } collaborative group & know-what & know-how & know-why & care-why \\
The first group & -0.19 & -0.36 & -0.55 & -0.40 \\
The second group & -0.14 & -0.18 & -0.37 & -0.60 \\
\hline
\end{tabular}

The adaptive knowledge assessments of individual students are set by differentiation of the adaptive knowledge assessments of the corresponding collaborative groups with taking into account the values of the knowledge development coefficient. It motivates students to gain lacking knowledge through collaborative work on a group project.

The value of the knowledge development coefficient for first collaborative group regarding know-what sub-component is higher than the coefficient value regarding know-how sub-component. Hence, the adaptive knowledge assessment regarding know-what sub-component should be less than the adaptive assessment regarding know-how sub-component for students from this collaborative group. The value of the knowledge development coefficient regarding care-why sub-component is higher than the coefficient value regarding know-why sub-component. Consequently, the adaptive knowledge assessment regarding care-why sub-component should be less than the adaptive assessment regarding know-why sub-component.

The adaptive assessments of knowledge for students of the second collaborative group are set on the basis of similar reasoning. Difference of the adaptive assessments is determined proportionally by difference of the values of knowledge development coefficient. The adaptive knowledge assessments of students are represented by Table 10 .

Table 10. The adaptive knowledge assessments of the collaborative group students

\begin{tabular}{ccc}
\hline The knowledge sub-components & \multicolumn{2}{c}{ The adaptive assessments of students } \\
\cline { 2 - 3 } know-what & the first group & the second group \\
know-how & 14 & 13 \\
know-why & 26 & 27 \\
care-why & 35 & 43 \\
\hline
\end{tabular}

Step5. Assessing student knowledge after completion of the group projects

The aim is assessment of the knowledge gained by each student after completion of the group projects. Assessment is realized by an instructor through the control tests of different complexity regarding the various knowledge components. A student who passes the control tests is considered to have mastered the corresponding knowledge. Then assessment of a student equals the adaptive assessment as set for the student from a collaborative group. If a student doesn't answer the control tests correctly or completely, then the corresponding assessment is marked.

Example8.Assessments of students regarding knowledge sub-components received after completion of the group projects are represented by Table 11. The total knowledge assessments of students (regarding knowledge component) are shown in the last row of the Table 11.

Table 11. The student assessments after completion of the group projects

\begin{tabular}{|c|c|c|c|c|c|c|c|}
\hline \multirow[t]{2}{*}{$\begin{array}{l}\text { The adaptive knowledge assessments } \\
\text { of the first group students regarding } \\
\text { knowledge sub-components }\end{array}$} & \multicolumn{3}{|c|}{$\begin{array}{l}\text { The knowledge } \\
\text { assessments of the first } \\
\text { group students }\end{array}$} & \multirow[t]{2}{*}{$\begin{array}{l}\text { The adaptive knowledge assessments } \\
\text { of the second group students } \\
\text { regarding knowledge sub-components }\end{array}$} & \multicolumn{3}{|c|}{$\begin{array}{l}\text { The knowledge } \\
\text { assessments of the } \\
\text { second group students }\end{array}$} \\
\hline & $\mathrm{S}_{1}$ & $\mathrm{~S}_{3}$ & $\mathrm{~S}_{5}$ & & $\mathrm{~S}_{2}$ & $\mathrm{~S}_{4}$ & $\mathrm{~S}_{6}$ \\
\hline know-what(14) & 13 & 10 & 11 & know-what(13) & 13 & 12 & 11 \\
\hline know-how(26) & 25 & 23 & 22 & know-how(17) & 16 & 15 & 14 \\
\hline know-why(35) & 31 & 28 & 27 & know-why(27) & 24 & 18 & 17 \\
\hline care-why (25) & 22 & 18 & 15 & care-why(43) & 42 & 40 & 38 \\
\hline The total knowledge assessments & 91 & 79 & 75 & The total knowledge assessments & 95 & 85 & 80 \\
\hline
\end{tabular}

Step6. Evaluating the development of students' knowledge 
The aim is to evaluate of knowledge dynamics resulted by adaptive $\mathrm{KM}$ of students. Evaluation of knowledge dynamics is realized by comparison of the values of knowledge development coefficient calculated on the basis of knowledge assessments after completion of first and second stages of PBL.

The values of knowledge development coefficient of students are calculated by using a formula:

$$
\mu\left(\mathrm{k}_{\mathrm{i}}\right)=\left(\mathrm{g}\left(\mathrm{k}_{\mathrm{i}}\right)-\mathrm{g}^{\mathrm{b}}\left(\mathrm{k}_{\mathrm{i}}\right)\right) / \mathrm{g}^{\mathrm{b}}\left(\mathrm{k}_{\mathrm{i}}\right), \quad-1<\mu\left(\mathrm{k}_{\mathrm{i}}\right) \leq 0
$$

where

$\mu\left(\mathrm{k}_{\mathrm{j}}\right)$ is a knowledge development coefficient of a student regarding $\mathrm{k}_{\mathrm{i}}$ sub-component;

$\mathrm{g}\left(\mathrm{k}_{\mathrm{i}}\right)$ is knowledge assessment of a student regarding $\mathrm{k}_{\mathrm{j}}$ sub-component;

$\mathrm{g}^{\mathrm{b}}\left(\mathrm{k}_{\mathrm{j}}\right)$ is basic assessment of student knowledge regarding $\mathrm{k}_{\mathrm{j}}$ sub-component.

Example9.The basic (initial) assessment of student knowledge regarding know-what sub-component is $30 \%$ (Table1). The formative knowledge assessment of student $\mathrm{s}_{1}$ regarding this sub-component received after completion of first stage of PBL is $26 \%$ (Table4). Then, the value of knowledge development coefficient of student $\mathrm{s}_{1}$ regarding know-what sub-component calculated by formula (2) equals -0.13. The basic (adaptive) knowledge assessment of student $\mathrm{s}_{1}$ regarding know-what sub-component is $14 \%$ (Table10). The knowledge assessment of student $\mathrm{s}_{1}$ regarding this sub-component received after completion of second stage of PBL is 12\% (Table11). Then, the value of coefficient of knowledge development in student $\mathrm{s}_{1}$ regarding know-what sub-component calculated by formula (2) equals - 0.07 .

The basic assessment of student knowledge regarding knowledge component is $100 \%$ (Table1and Example 6). Then, the basic knowledge assessment of group involving three students regarding knowledge component is $300 \%$.

The total formative knowledge assessments of the first and the second collaborative groups after completion of the first PBL stage are 195, and 235, accordingly (Example 5). Hence, the values of knowledge development coefficient of the first and the second collaborative groups are -0.35 and -0.21 , accordingly. The values are calculated by formula (1).

The total knowledge assessments of the first and the second collaborative groups after completion of the second PBL stage determined on the basis of data from Table11 are 245, and 260, accordingly. Hence, the values of coefficient of knowledge development of the first and the second collaborative groups calculated by formula (1) equals -0.18 and -0.13 , accordingly.

The calculated values of coefficient of knowledge development in students regarding knowledge sub-components are represented by Table 12 .

Table 12. The values of the knowledge development coefficient

\begin{tabular}{cccccccc}
\hline & & \multicolumn{3}{c}{ The values of the knowledge development coefficient } \\
\multirow{2}{*}{$\begin{array}{c}\text { The name of PBL } \\
\text { stage }\end{array}$} & \multicolumn{3}{c}{ The first group } & \multicolumn{3}{c}{ The second group } \\
\cline { 2 - 8 } & kno-components & $\mathrm{S}_{1}$ & $\mathrm{~S}_{3}$ & $\mathrm{~S}_{5}$ & $\mathrm{~S}_{2}$ & $\mathrm{~S}_{4}$ & $\mathrm{~S}_{6}$ \\
\multirow{3}{*}{ The first PBL stage } & know-what & -0.13 & -0.23 & -0.20 & -0.07 & -0.17 & -0.20 \\
& know-why & -0.25 & -0.35 & -0.48 & -0.08 & -0.13 & -0.35 \\
care-why & -035 & -0.65 & -0.65 & -0.15 & -0.45 & -0.50 \\
The second PBL stage & know-what & -0.40 & -0.30 & -0.50 & -0.20 & -0.20 & -0.40 \\
& know-how & -0.07 & -0.29 & -0.21 & 0 & -0.08 & -0.15 \\
& know-why & -0.04 & -0.12 & -0.15 & -0.06 & -0.12 & -0.18 \\
& care-why & -0.11 & -0.20 & -0.23 & -0.11 & -0.33 & -0.37 \\
& -0.12 & -0.28 & -0.40 & -0.02 & -0.07 & -0.11 \\
\hline
\end{tabular}

4. Analysis of Knowledge Development Management

Analysis of data from Table12 reveals the development of students' knowledge of the first and second collaborative groups regarding all the knowledge sub-components. Furthermore, progress of the development of students' knowledge regarding know-how sub-component is significantly higher than one regarding know-what sub-component for both collaborative groups.

The more adaptive assessment of students from the first collaborative group regarding know-why sub-component brings the more progress in development their knowledge regarding this sub-component compared with progress in knowledge development regarding care-whysub-component. 
The more adaptive assessment of students from the second collaborative group regarding care-why sub-component causes the more progress in development their knowledge regarding this sub-component compared with progress in knowledge development regarding know-why sub-component.

Conducted analysis demonstrates the effectiveness of managing the development of students' knowledge through setting adaptive assessment for different knowledge sub-component.

Comparing the values of the knowledge development coefficient of the first and the second collaborative groups (Example 9) allows concluding that the second group has the more progress in the development of students' knowledge then the first group. It serves as evidence of the more effective collaboration of students and the more efficiency of the shared accountability.

\section{Conclusion}

The proposed six-step approach sets the order of adaptive management of the developing students' knowledge in the comprehensive PBL environment. Organizing subject study through two-stage PBL and taking into account the specific characteristics of the comprehensive PBL environment allow shaping adaptive knowledge management (KM) process and defining the balance between personalized and collaborative learning.

The created mechanism for adaptive management of the development of students' knowledge promotes adaptive self-formation of knowledge-heterogeneous collaborative groups by sharing accountability among students for results of performing project tasks. It provides adaptation of an instructor's assessments to knowledge dynamics of individual students and collaborative groups. The mechanism realizes adaptive choice of the projects of suitable complexity for the collaborative groups and control tests for monitoring and assessment of individual students. It also adjusts an instructor's control questions to complexity levels of the projects performed by the collaborative groups.

Knowledge dynamics of students is evaluated by the proposed coefficient of knowledge development. It serves as a constructive mean of estimating the approach.

Further research will be directed towards development of a practical method and a supporting system for adaptive management of the development of students' knowledge based on the proposed approach.

\section{References}

Aguilar, G., \& Kaijiri, K. (2007). Design overview of an adaptive computer-based assessment system, Interactive Educational Multimedia, 14, 116-130. http://www.raco.cat/index.php/iem/article/viewFile/205325/273863

Altinay, F., Dagli, G., \& Kasimoglu, S. (2015). Knowledge management and project based learning in higher education, Lap Lambert Academic Publishing

Anderson, T. (2008). The theory and practice of online learning, Athabasca University Press

Barkley, E., Cross, K. P., \& Howell, M. C. (2004). Collaborative learning techniques: A handbook for college faculty (Paperback), 1 edition, San Francisco, CA: Jossey-Bass.

Bender, W. N. (2012). Project-based learning:differentiating instruction for the 21st century

Brusilovsky, P., \& Maybury, M. T. (2002). From adaptive hypermedia to the adaptive web. Communications of the ACM, 45(5), 30-33. http://dx.doi.org/10.1145/506218.506239

Brusilovsky, P., \& Peylo, C. (2003). Adaptive and intelligent web-based educational systems.International Journal of Artificial Intelligence in Education, 13, 156-169.

Burgos, D., Tattersall, C., \& Koper, E. J. R. (2006). Representing adaptive e-learning strategies in IMS learning design, Proceedings of the International Workshop in Learning Networks for Lifelong Competence Development, 54-60, March, 30-31, Sofia, Bulgaria: TEN Competence Conference. http://hdl.handle.net/1820/601

Coakes, E., \& Clarke, S. (2006). Encyclopedia of communities of practice information and knowledge management, Idea Group Inc. http://dx.doi.org/10.4018/978-1-59140-556-6

Corwin, B., John, D., Brown, A. L., \& Cocking, R. R. (1999). How people learn: brain, mind, experience and school, Washington DC, The National Academies Press

Dalkir, K., \& Liebowitz, J. (2011). Knowledge management in theory and practice, second edition, Cambridge, MA: The MIT Press

Dongsik, K., \& Seunghee, L. (2002). Designing collaborative reflection supporting tools in E-project-based learning environments, Journal of Interactive Learning Research, 13(4), 375-392.

Doyle, T., \& Taqq, J. (2008). Helping students learn in a learner-centered environment: A Guide to facilitating learning 
in higher education, Sterling, Virginia: Stylus Publishing

Dym, C., Agogino, A., Eris, O., Frey, D., \& Leifer, L. (2005). Engineering design thinking, teaching and learning, Journal of Engineering Education, 94(1), 103-120. http://dx.doi.org/10.1002/j.2168-9830.2005.tb00832.x

Edwards, J. S., editor (2015). The essentials of knowledge management, UK: Palgrave Macmillan. http://dx.doi.org/10.1057/9781137552105

Ettington, D. R., \& Camp, R. R. (2002). Facilitating transfer of knowledge between group projects and work teams, Journal of Management Education, 26(4), 356-379. http://dx.doi.org/10.1177/105256290202600404

Felder, R. M., \& Brent, R. (2001). Effective strategies for cooperative learning. http://www2.ncsu.edu/unity/lockers/users/f/felder/public/papers/CL

Garner, S. (2010). Personal knowledge management and student learning, Journal of Business \& Economics Research, 8(12), 43-48. http://dx.doi.org/10.19030/jber.v8i12.779

Garrison, D. R. (1992). Critical thinking and self-directed learning in adult education: an analysis of responsibility and control issues, Adult Education Quarterly, 42(3), 136-148. http://dx.doi.org/10.1177/074171369204200302

Jonassen, D. (2004). Design of constructivist learning environment. http://www.coe.missouri.edu/ jonassen/courses/CLE/

Krauss, J. I., \& Boss, S. K. (2013).Thinking through project-based learning: guiding deeper inquiry, Corwin; 1edition

Larmer, J., \& Mergendoller, J. (2015). Setting the standard for project based learning, ASCD

Lazarinis, F., Green, S., \& Pearson, E. (2010). Creating personalized assessments based on learner knowledge and objectives in a hypermedia Web testing application. Computers \& Education, 55(4), 1732-1743. http://dx.doi.org/10.1016/j.compedu.2010.07.019

Livingstone, D. W., \& Guile, D. (2012). The knowledge economy and lifelong learning: a critical reader, Rotterdam: Sense Publishers. http://dx.doi.org/10.1007/978-94-6091-915-2

Lopez, A. V. et al. (2002). Embedding facilitation in group support systems to manage distributed group behavior, Proceedings of the 35th Annual Hawaii International Conference on System Sciences, 7-10 Jan. http://dx.doi.org/10.1109/HICSS.2002.993939

Markham, T. (2012). Project based learning. design and coaching guide, San Rafael, CA: Heart IQ Press

Mcinerney, C. R., \& Day, R. E. (2007). Rethinking knowledge management: from knowledge objects to knowledge processes, 1 edition, Springer Berlin Heidelberg. http://dx.doi.org/10.1007/3-540-71011-6

Mennin, S. (2007). Small-group problem-based learning as a complex adaptive system, teaching and instructor education, 23(3), 303-313. http://dx.doi.org/10.1016/j.tate.2006.12.016

Mergendoller, J., \& Thomas, J. W. (2005). Managing project-based learning: principles from the field. http://www.bie.org/tmp/research/researchmanagePBL.pdf

Mergendoller, J., Markham, T., Ravitz, J., \& Larmer, J. (2006). Pervasive management of project based learning: teachers as guides and facilitators, Buck Institute for Education. http://bie.org/images/uploads/general/25a07c3bc2b40118ba8b03334fe16d58.pdf

Oliver, R., \& Herrinton, J. (2001). Teaching and learning online. A beginner guide to e-learning and e-teaching in higher education, Centre for Research in Information Technology and Communications

Papanastasiou, E. (2014). Adaptive assessment, Encyclopedia of Science Education, Springer, 1-2.

Petrides, L. A., \& Nodine, T. R. (2003). Knowledge management in education: defining the landscape. The Institute for the Study of Knowledge Management in Education. http://files.eric.ed.gov/fulltext/ED477349.pdf

Prusak, L., \& Cranefield, J. (2016). Managing your own knowledge: a personal perspective.In Pauleen, D.J., \& Gorman, G. E. (editors).Personal Knowledge Management: Individual, Organizational and Social Perspectives, Gower

Quinn, J., Anderson, P., \& Finkelstein, S. (1998). Managing professional intellect, Harvard Business Review on Knowledge Management, Harvard Business School Press, 181-205.

Ravitz, J. (2009). Introduction: Summarizing findings and looking ahead to a new generation of PBL Research. Interdisciplinary Journal of Problem-based Learning, 3(1). http://dx.doi.org/10.7771/1541-5015.1088

Reeves, B. D. (2004). Accountability for learning: how teachers and school Leaders can take charge, Association for Supervision \& Curriculum Deve. 
Rooney, D., McKenna, B., \& Liesh, P. (2014). Wisdom and management in the knowledge economy, Routledge, Reprint edition

Sallis, E., \& Jones, G. (2002). Knowledge management in education: enhancing learning and education, London: Kogan Page

Savery, J. R. (2006). Overview of problem-based learning: definitions and distinctions, The Interdisciplinary Journal of Problem-based learning, 1(1).

Shavelson, R. (2009). Measuring college learning responsibly: accountability in a new era, Stanford University Press

Sherif, K. (2006). An adaptive strategy for managing knowledge in organizations, Journal of Knowledge Management, 10(4), 72-80. http://dx.doi.org/10.1108/13673270610679372

Soller, A. (2007). Adaptive support for distributed collaboration. In: Brusilovsky A., Kobsa A. \& Nejdl W. (eds), The Adaptive Web. Methods and Strategies of Web Personalization, Springer. http://dx.doi.org/10.1007/978-3-540-72079-9_19

Solomon, G. (2003). Project-based learning: a primer. Technology and Learning, 23(6).

Stahl, G. (2006). Group cognition: computer support for building collaborative knowledge (Acting with Technology), The MIT Press

Stanton, P., \& Fairfax, D. (2007). Establishing individual accountability for learning in an exam-less, group project course, Proceedings of the 2007 Middle Atlantic Section Fall Conference of the American Society for Engineering Education, 1-9.

Thomas, J. W. (2000). A review of research on project-based learning.

Thomas, J. W. (2000). A review of research on project-based learning. http://www.autodesk.com/foundation

Tilchin, O., \& Kittany, M. (2016). Adaptive knowledge management of project-based learning, Journal of Education and Training Studies, 4(6), 137-144. http://dx.doi.org/10.11114/jets.v4i6.1461

Tiwana, A. (1999). The knowledge management toolkit. Practical techniques for building a knowledge management system, Prentice Hall

Vasilyeva, E., Pechenizkiy, M., \& Puuronen S. (2005). Knowledge management challenges in web-based adaptivee-learning systems, Proceedings of I-KNOW'05 Graz, Austria, June 29 - July 1, 112-119.

Weinberger, A. et al. (2003). Facilitating collaborative knowledge construction in computer-mediated learning with structuring tools, Research report No.158, Munich, Germany: Ludwig-Maximilians-University, Institute for Empirical Pedagogy and Pedagogical Psychology. http://epub.ub.uni-muenchen.de/266/1/FB_158

Zaim, H., Tatoglu, E., \& Zaim, S. (2007). Performance of knowledge management practices: a causal analysis", Journal of Knowledge Management, 11(6), 54 - 67. http://dx.doi.org/10.1108/13673270710832163

This work is licensed under a Creative Commons Attribution 3.0 License. 